\title{
Evaluation of oncological and functional outcomes in robot-assisted partial nephrectomy for renal tumors with intermediate and high risk RENAL nephrometry scores
}

\section{RENAL nefrometri skoru orta ve yüksek risk grubu renal kitlelerde robot yardımlı parsiyel nefrektominin onkolojik ve fonksiyonel sonuçlarının değerlendirilmesi}

\author{
$\underline{\text { Mehmet Salih Boğa }}{ }^{1}, \underline{\text { Ekrem Islamoglu }}^{1}, \underline{\text { Kaan Karamık }}^{1}, \underline{\text { Cağatay Özsoy }}^{1}, \underline{\text { murat savas }}^{2}, \underline{\text { Mutlu Ates }}^{1}$ \\ ${ }^{1}$ Sağlık Bilimleri Üniversitesi, Antalya Eğitim ve Araştırma Hastanesi, Üroloji Bölümü, Antalya \\ ${ }^{2}$ Antalya Memorial Hastanesi, Üroloji Bölümü, Antalya
}

Dergiye Ulaşma Tarihi:17.07.2020 Dergiye Kabul Tarihi: 11.08.2020 Doi: 10.5505/aot.2020.13284

\section{ÖZET}

GİRIŞ ve AMAÇ: RENAL nefrometri skoru 7 ve üzerinde olan renal kitlelerde robot yardımlı parsiyel nefrektominin perioperatif, onkolojik ve fonksiyonel sonuçlarının değerlendirilmesi.

YÖNTEM ve GEREÇLER: Nisan 2015- Mart 2019 tarihleri arasında robotic parsiyel nefrektomi uygulanan ve nefrometri skoru 7 ve üzeri olan vakaların demografik, perioperatif ve postoperatif verileri retrospektif olarak değerlendirildi. Soliter böbrekli, sıcak iskemi uygulanmayan, multiple renal kitlesi olan ve retroperitoneal teknikle parsiyel nefrektomi uygulanan hastalar çalışma dışı bırakıldı.

BULGULAR: Hastaların ortalama yaşı $58.08 \pm 12.71$ yıl idi. Ortalama tümör çapı, RENAL skor, preoperative eGFR değerleri sırasıyla $4.19 \pm 1.56 \mathrm{~cm}, 7.88 \pm 1.12$ ve $78.73 \pm 18.10 \mathrm{ml} / \mathrm{min} / 1.73 \mathrm{~m}^{2}$ idi. Ortalama operasyon süresi, kanama miktarı, hastanede kalış süresi sırasıyla $156.15 \pm 45.70 \mathrm{dk}, 139.06 \pm 72.96 \mathrm{~mL}$ ve $3.58 \pm 1.03$ gün şeklindeydi. Açığa ve radikal nefrektomiye dönüş izlenmedi. Cerrahi sınır pozitifliği 2 (4.2\%) hastada izlendi.

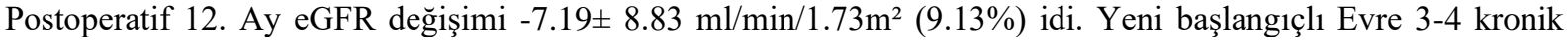
böbrek yetmezliği $\left(\mathrm{eGFR}<60 \mathrm{ml} / \mathrm{min} / 1.73 \mathrm{~m}^{2}\right)$ oranı $6.3 \%$ olarak saptandı. Hastaların ortalama takip süresi 35.08 \pm 11.09 ay idi. Takip boyunca kansere bağlı ölüm izlenmezken, genel sağkalım $95.8 \%$ olarak saptandı.

TARTIŞMA ve SONUÇ: Robot yardımlı parsiyel nefrektomi RENAL skoru orta-yüksek risk grubu renal kitlelerde güvenilir onkolojik ve fonksiyonel sonuçlarla başarıyla uygulanabilir cerrahi bir yöntemdir.

Anahtar Kelimeler: renal kitle, robot, parsiyel nefrektomi, RENAL skor

\section{ABSTRACT}

INTRODUCTION: To evaluate the perioperative, oncological and functional outcomes of robot-assisted partial nephrectomy in renal masses with a RENAL nephrometry score $\geq 7$.

METHODS: Demographics, perioperative and postoperative outcomes of robot-assisted partial nephrectomy with a RENAL nephrometry score $\geq 7$ who operated between April 2015 and March 2019 were retrospectively evaluated. Patients with solitary kidney, zero ischemic, multiple renal mass and partial nephrectomy with retroperitoneal technique were excluded from the study.

RESULTS: The mean age of the patients was $58.08 \pm 12.71$ years. Mean tumor diameter, RENAL score, preoperative eGFR values were $4.19 \pm 1.56 \mathrm{~cm}, 7.88 \pm 1.12$ and $78.73 \pm 18.10 \mathrm{ml} / \mathrm{min} / 1.73 \mathrm{~m}^{2}$, respectively. The mean operation time, estimated blood loss, and length of hospital stay were $156.15 \pm 45.70 \mathrm{~min}, 139.06 \pm$ $72.96 \mathrm{~mL}$ and $3.58 \pm 1.03$ days, respectively. No conversion to open or radical nephrectomy was observed. Positive surgical margin was observed in $2(4.2 \%)$ patients. The 12th month postoperative eGFR change was $-7.19 \pm 8.83$ $\mathrm{ml} / \mathrm{min} / 1.73 \mathrm{~m}^{2}(9.13 \%)$. The rate of new-onset Stage 3-4 chronic kidney disease $\left(\mathrm{eGFR}<60 \mathrm{ml} / \mathrm{min} / 1.73 \mathrm{~m}^{2}\right)$ was $6.3 \%$. The mean follow-up period was $35.08 \pm 11.09$ months. Overall survival was $95.8 \%$, while cancerrelated death was not observed during follow-up.

DISCUSSION AND CONCLUSION: Robot-assisted partial nephrectomy with intermediate and high risk RENAL nephrometry scores is a safe surgical method that can be applied successfully with comparable oncological and functional results.

Keywords: renal tumor, robotics, partial nephrectomy, RENAL score 


\section{GİRIS}

Küçük boyutlu renal kitlelerde, radikal nefrektomiyle benzer onkolojik sonuçlar ve uzun dönem renal fonksiyonlara olan katkıs1 nedeniyle nefron koruyucu cerrahi önerilmektedir (1). Radyolojik tan1 yöntemlerinin kullanımının artmasıyla birlikte küçük boyutlu renal kitlelerin tanısında insidental olarak ve buna parallel olarak parsiyelnefrektomi kullanımında artış olmuştur.

Uzun dönem renal fonksiyonlara olan katkısıyla morbidite ve mortalitede azalmalar sağlaması nedeniyle parsiyelnefrektominin yüksek risk RENAL skorlu hastalarda da uygulanması artış göstermektedir $(2,3)$.

İdeal bir parsiyelnefrektomide cerrahi sinırın negative olmasi, renal fonksiyonlarda minimal bozulma ve komplikasyon olmaması en önemli üç beklenti olup trifecta olarak tanımlanmaktadır (4).

Laparoskopik ve robotik cerrahi gibi minimal invasive teknikler parsiyelnefrektomideaçık cerrahiye benzer onkolojik sonuçlarla başarıyla uygulanmakla birlikte postoperative ağrı, hastanede kalış süresi ve kozmetik sonuçlar bakımından açık cerrahiye gore avantaj sağlamaktadır (5).

$\mathrm{Bu}$ çalışmada kliniğimizde uyguladığımız RENAL skoru orta-yüksek risk grubunda olan vakaların onkolojik ve fonksiyonel verilerini sunmaktır.

\section{MATERYAL ve METOD}

Çalışmaya Nisan 2015 ve Mart 2019 tarihleri arasında transperitonealyolla robotik yardımlı parsiyelnefrektomi (RYPN) uyguladığımız RENAL nefrometri skoru 7 ve üzerinde olan hastalar dahil edildi. Soliter böbrekli, zeroiskemik olarak yapılan, retroperitoneal teknik uygulanan, takip süresi 1 yıldan az ve verileri eksik olan hastalar çalışma dışı birakild1.

Çalışmaya 37'si $\operatorname{erkek(77.1\% )\quad 11'}$ $\operatorname{kad} ı(22.9 \%)$ olmak üzere toplam 48 hasta dahil edildi. Renal kitlelerin tanısında kontrastlı tomografi veya manyetik resonans görüntüleme kullanıldı. Nefrometri risk sinıflaması RENAL (R (radius), E (exophytic/ endophytic), $\mathrm{N}$ (nearness), A (anterior), and L (location)) skorlama sistemine göre yapıldı (6).

Hastaların demografik bilgileri, tümör boyut ve RENAL skorları, ameliyat süresi, kanama miktarı, sıcak iskemi süresi, açığa veya radikal nefrektomiye dönüş bilgileri, dren çıkartılma ve hastanede kalış süreleri kaydedildi. Ameliyat süresi ilk cilt insizyonundan ameliyat bitiminde insizyonun kapatılması arasında geçen süre olarak hesaplandı. Sicak iskemi süresi renal artere buldogklempinin koyulması ve çıkartılması arasında geçen süre olarak kaydedildi.

Patolojik parametrelerden, histolojik alt tip, patolojik evre, Furhmangrade ve cerrahi sınır pozitifliği bilgileri kaydedildi. Operasyon öncesi ve operasyondan 1 yll sonraki tahmini glomerüler filtrasyon oran1 (estimated glomerular filtration rate- eGFR) değerleri Modification of Diet in RenalDisease (MDRD) formülüne göre hesaplandı (7). Bu süre zarfında ki eGFR değişimleri kaydedildi.

\section{Cerrahi Teknik}

Çalışmaya dahil edilen tüm hastalara daha öncesinde tariflenen yöntemle 4 kollu daVinciXi robotik sistem (IntuitiveSurgical, CA, USA) kullanilarak transperitoneal yaklaşımlı parsiyelnefrektomi uygulandı (8). Cerrahi tekniğimiz özetle; hastalara genel anesteziyi takiben tömör tarafina göre sağ veya sol lateral dekübitis ve sirt kısmı $45^{\circ}$ yan duracak şeklide pozisyon verildi. Robot kollarının yerleştirilmesinde yeterli alan sağlamak için masa hiperekstansiyona alındı. Umblikusun yaklaşı $3-4 \mathrm{~cm}$ superiorundan rektus abdominus kası lateralinden Veress iğnesi ile girilerek intraabdominal basınç 12-15 $\mathrm{mmHg}$ olacak şekilde pnömoperitoneum sağland1. Dördü robotik port,biri asistan portu olmak üzere toplam 5 adet port yerleştirildi. Robot kolları hastanın sirt bölgesinden yaklaştırılarak hastanın önünde bulunan robotik portlara kenetlendi. Cerrahi asistan hastanın önyan bölgesinde durarak robotik enstürmanların değiştirlmesi, aspiratör kullanımı, sütur materyali iletimi ve klip yerleştirilmesinde görev aldı.

Transperitoneal geçiş sağlandıktan sonra kolon Told-line'dan mediale doğru medialize edildi. Hepatorenal veya splenoligamanların disseksiyonu takiben psoas üzerinden üreter ve gonodal ven bulundu, kranial yönde ilerlenerek hiluma ulaş1ld, arter ve ven ayrı ayrı diseke edildi. Ardından tümöral alan dışındaki perinefrik yağ dokuları disseke edildi. Yaklaşık $5 \mathrm{~mm}$ lik sağlam dokuyuda 
içine alacak şekilde renal kitlenin etrafi monopolar koterle işaretlendi, ardından renal arter Buldog klemple klemplenerek koterli işaretli alan soğuk biçakla rezeke edilerek kitle çıkartıldı. Tümör yatağındaki kollektör sistem ve vasküler yapılar 3/0 V-Lock ve renal parankimde $2 / 0$ Vicryl veya $2 / 0$ Monocryl yaklaştırma süturları ile süture edildi. Kanama kontrolü sağlandıktan sonra Buldog klemp açılarak sıcak iskemi sonlandırıldı. Karın içi organlar kontrol edilip silikon dren konularak işlem sonlandırıldi.

\section{Istatistiksel analiz}

İstatistiksel analiz IBM Statistical Package for the Social Sciences soft version 22.0 (IBM SPSS Corp.; Armonk, NY, USA) programı kullanılarak yapıldı. Değişkenlerin dağılımları analiz edildikten sonra. tanımlayıcı istatistikler kullanılarak bulgular elde edildi. Değerler ortalama \pm standart sapma veya sayı (\%) şeklinde belirtildi.

\section{BULGULAR}

Hastaların demografik özellikleri ve renal kitlelerin karakteristikleri Tablo 1 de gösterilmektedir. Robotik parsiyelnefrektomi uygulanan ve RENAL skoru orta-yüksek risk grubunda olan toplam 48 hasta çalışmaya dahil edildi. Hastaların ortalama yaşı,tümör çap1, RENAL skoru ve operasyon öncesi eGFR değerleri $58.08 \pm 12.71 \mathrm{y} 11,4.19 \pm 1.56 \mathrm{~cm}, 7.88$ \pm 1.12 ve $78.73 \pm 18.10 \mathrm{ml} / \mathrm{min} / 1.73 \mathrm{~m}^{2}$ idi.
Tümörlerin 37.5\%'u sağ tarafa, 62.5\%'u sol tarafa lokalizeydi.

Ortalama sicak iskemi süresi, kanama miktarı ve operasyon süresi sirasıyla $27.25 \pm$ $5.74 \mathrm{dk}, 139.06 \pm 72.96 \mathrm{mLve} 156.15 \pm 45.70$ dkidi. Kan transfüzyonu $5(10.4 \%)$ hastaya yapıldı. Açı̆̆a veya radikal nefrektomiye dönüş hastaların hiç birinde izlenmedi. Hastalar genelde drenlerinin alınışının ertesi günü taburcu edildi. Ortalama dren ve taburculuk süresi $2.54 \pm 0.68$ ve $3.58 \pm 1.03$ gün olarak belirlendi (Tablo 2).

Intraoperatif $1(2.1 \%)$ hastada barsak yaralanması izlendi ve primer onarım uyguland. Takip süresince bu hastada ek problem izlenmedi. Ameliyat sonrası erken dönemde (0-30 gün) 6 (12.5\%) hastada Clavien 1-2 komplikasyon izlenirken geç dönem (31-90 gün) komplikasyon izlenmedi. Cerrahi sınır pozitifliği $2(4.2 \%)$ hastada izlendi. Ortalama takip süresi $35.08 \pm 11.09$ ay idi. Takip süresince kansere bağlı ölüm izlenmezken, genel sağ kalım 95.8 \% olarak belirlendi (Tablo $3)$.

On ikinci ay sonunda eGFR düşüşü $7.19 \pm 8.83 \mathrm{ml} / \mathrm{min} / 1.73 \mathrm{~m}^{2} \quad(9.13 \%)$ olarak saptand1. Operasyon öncesi Evre 3-4 kronik böbrek yetmezliği olan hasta sayısı 7 (14.6\%) iken operasyon sonrasi takip boyunca yeni başlangiçlı Evre 3-4 böbrek yetmezliği 3 (6.3\%) olarak saptandi (Tablo 4).

Tablo 1.Hastaların demografik bilgileri ve tumor özellikleri

\begin{tabular}{ll}
\hline Değişkenler & RYPN (n = 48) \\
\hline Ortalama yaş, yıl & $58.08 \pm 12.71$ \\
Cinsiyet & $37(77.1 \%)$ \\
Erkek & $11(22.9 \%)$ \\
Kadın & $18(37.5 \%)$ \\
Tümör yönü & $30(62.5 \%)$ \\
$\quad$ Sağ & $4.19 \pm 1.56$ \\
Sol & $7.88 \pm 1.12$ \\
Ortalama tumor çapı, cm & $27(56.3 \%)$ \\
Ortalama RENAL skoru & $10(20.8 \%)$ \\
Hipertansiyon & $78.73 \pm 18.10$ \\
\hline Diyabet & \\
Ameliyat öncesi ortalama eGFR, $\mathbf{m l} / \mathbf{m i n} / \mathbf{1 . 7 3 m ^ { 2 }}$ & \\
\hline
\end{tabular}

RYPN= robot yardımlıparsiyelnefrektomi, eGFR = estimated glomerular filtration rate, RENAL = R (radius), E (exophytic/ endophytic), N (nearness), A (anterior) and L (location). 
Tablo 2. Perioperatif veriler

\begin{tabular}{ll}
\hline Değişkenler & RYPN $\mathbf{( n = 4 8 )}$ \\
\hline Ameliyat süresi, dakika & $156.15 \pm 45.70$ \\
Kanama miktarı, mL & $139.06 \pm 72.96$ \\
Sıcak iskemi süresi, dakika & $27.25 \pm 5.74$ \\
Açığa dönüş oranı & 0 \\
Radikal nefrektomiye dönüş oranı & 0 \\
Hastanede kalış süresi, gün & $3.58 \pm 1.03$ \\
Dren süresi, gün & $2.54 \pm 0.68$ \\
\hline
\end{tabular}

RYPN= robot yardımlı parsiyel nefrektomi

Tablo3: Ameliyat sonrası patolojik, komplikasyon ve sağkalım oranları

\begin{tabular}{lc}
\hline Değişkenler & RYPN (n = 48) \\
\hline Patoloji tipi & \\
Berrak hücreli & $27(56.3 \%)$ \\
Kromofob & $1(2.1 \%)$ \\
Papiller & $8(16.7 \%)$ \\
Anjiomiyolipom & $2(4.2 \%)$ \\
Onkositom & $3(6.3 \%)$ \\
Diğer benign & $7(14.6 \%)$ \\
Furhman derecesi & \\
I & $3(6.3 \%)$ \\
II & $28(58.3 \%)$ \\
III & $7 n(14.6 \%)$ \\
IV & $10(20.8 \%)$ \\
Evreleme & $23(47.9 \%)$ \\
$\quad$ T1a & $19(39.6 \%)$ \\
T1b & $6(12.5 \%)$ \\
T2a & \\
Komplikasyonlar & $6(12.5 \%)$ \\
Clavien 1-2 & 0 \\
Clavien 3-5 & $5(10.4 \%)$ \\
Transfüzyon uygulaması & $2(4.2 \%)$ \\
Cerrahi sınır pozitifliği & $46(95.8 \%)$ \\
Genel sağ kalım & $35.08 \pm 11.09$ \\
\hline Takip süresi, ay &
\end{tabular}

RYPN= robot yardımlı parsiyel nefrektomi

Table 4. Operasyon öncesi ve sonrasında ortaya çıkan Evre 3-4 KBY ve eGFR değişim oranları

\begin{tabular}{ll}
\hline Değişkenler & RYPN $(\mathbf{n}=\mathbf{4 8})$ \\
\hline Takip süresi, ay & $35.08 \pm 11.09$ \\
Operasyon öncesi eGFR & $78.73 \pm 18.09$ \\
Operasyon sonrası 12. ay eGFR & $71.52 \pm 17.94$ \\
eGFR değişimi, ml/min/1.73m² & $-7.19 \pm 8.83(9.13 \%)$ \\
Operasyon öncesi Evre 3-4 KBY & $7(14.6 \%)$ \\
Yeni başlangıçlı Evre 3-4 KBY & $3(6.3 \%)$ \\
\hline
\end{tabular}




\section{TARTIŞMA}

Renal fonksiyonlarda bozulma ile kardiovasküler hastalık arasında ilişkinin gösterilmesiyle birlikte nefron koruyucu cerrahinin önemi daha da belirgin hale gelmiştir (3). Bu nedenle Tla ve Tlb evre böbrek tümörlerinin tedavisinde rutin olarak parsiyelnefrektomi önerilmektedir (1). Hastanede kalış süresi, kanama miktarı ve estetik avantajları nedeniyle minimal invaziv teknikler açık cerrahiye tercih edilmektedir. Tümör kompleksitesi cerrahi ve onkolojik başarıyı etkileyen önemli bir faktördür (9). Tecrübeli merkezlerde seçilmiş endofitik tümörlerde LPN başarıyla uygulanabilirken (10)komplex tümörlerde 3D görüntü kalitesi ve ergonomik el hareketleri sağlaması gibi avantajlarıla robotik cerrahi, LPN ve APN ye alternatif olarak görünmektedir (9).

Yapılan çalışmalar RPN'nin kanama miktarının az, sicak iskemi süresinin ve hastanede kalıș süresinin kisa olması gibi avantajlar sağladığını göstersede RENAL nefrometri skoru $>7$ olan komplex kitlelerde RPN sonuçlarının bildirildiği yayın sayısı hala kisitlidir (11-13).

Tüm kanser cerrahisinde olduğu gibi parsiyelnefrektomide de en önemli beklenti cerrahi sınır negatifliğidir. Kompleks tümörlerde RPN uygulanan serilerde cerrahi sinır pozitifliği Deng ve ark.(12), Wang ve ark. (13), serilerinde sirasiyla $3.4 \%$ ve $1.2 \%$ olarak bildirdiler. Bizim serimizde cerrahi sınır pozitifliği 3.4\% ile literatürle benzerdi.

Deng ve ark. (12) RENAL skoru $>7$ olan renal kitlelerde yapmış oldukları çalışmalarında ameliyat süresi ve kanama zamanı $198.8 \mathrm{dk}$ ve $160 \mathrm{~mL}$ olarak bildirildi. Mevcut çalışmamızda bu değerler sırasıyla $156.15 \pm 45.70 \mathrm{dk}$ ve $139.06 \pm 72.96 \mathrm{~mL}$ idi. $\mathrm{Bu}$ değerlerin bizim çalışmamızda daha iyi olmasının sebebinin Deng ve ark çalışmasında RENAL skoru $>7$ olan T1b vakaları dahil edilirken bizim çalışmamızda RENAL skoru $>7$ olan T1a ve T1b hastaları birlikte değerlendirilmiş olmasından kaynaklanmış olabileceğini düşünmekteyiz. White ve ark. dabizim serimizle benzer özellikte vakalarla yapmış oldukları çalışmada bu değerleri $180 \mathrm{dk}$ ve 200 mLolarak bildirdiler (11).

RYPN'nin önemli avantajlarından birisi LPN ve APN'yegore hastanede kalış süresinin kısa olmasıdır. RENAL skoru $>7$ olan renal kitlelerle yapılan iki farkl1 RYPN serilerinde komplikasyon oranları $17.3 \%$ ve $20.7 \%$ olarak, hastanede kalış sürelerini ise sırasıyla 7.6 ve 7.5 gün olarak bildirdi. Bizim çalışmamızda komplikasyon oranı $12.5 \%$, hastanede kalış süresi ise $3.58 \pm 1.03$ gün olarak kaydedildi $(12,13)$. Hastanede kalış süresinin her iki seriye gore bizde daha düşük olmasının sebebinin komplikasyon oranımızın düşük olmasına bağlı olduğunu düşünmekteyiz.

Parsiyel nefrektomi sonrasi erken dönemde renal fonksiyonlarda bozulma sicak iskemi süresi ile ilişkiliyken, uzun dönem renal fonksiyonlarda bozulmanın nefron yani renal parankim kaybıyla ilişkili olduğu bildirilmiş̧ir. Yapılan çalışmalar sıcak iskemi süresi 25 dk'yı geçtikten sonra her dakika renal fonksiyonlarda bozulmayı arttıracağı bildirilse de bu sürenin 30 dk'nın üstünde olmadığı sürece uzun dönem renal fonksiyonları olumsuz etkilemeyeceği bildirilmiştir $(14,15)$.

Çalışmamızda sıcak iskemi süresi $27.25 \pm 5.74$ dakikaydı. $\mathrm{Bu}$ süre literatüre oranla kabul edilebilir bir değer olsa da nisbeten yüksekti. Nisbeten yüksek olmasının sebebinin, çalışmaya dahil edilen vakaların RENAL skoru orta ve yüksek risk $(>7)$ grubunda olmasının yanında, ögrenme eğrisinde yapılan vakalarında çalışmaya dahil edilmiş olmasına bağlı olduğunu düşünüyoruz.

Renal fonksiyonlarda bozulmanın göstergesi olarak kabul edilen eGFR düşüş oranına baktığımızda Wang ve ark.(13) RENAL skoru $>7$ olan renal kitlelerde yapmış oldukları çalışmalarında 6 ay sonunda eGFR düşüşünü $7.6 \%$ olarak bildirdiler. Bizim çalışmamızda 12 aylık eGFR düşüşü 9.13\% olarak kaydedildi. eGFR düşüşünün bizim çalışmamızda daha fazla olmasının sebebinin sıcak iskemi süresinin daha uzun $(27.25 \mathrm{dk}$ ve $20.5 \mathrm{dk}$ ) olmasına bağlı olabileceği gibi ölçüm yapılan sürelerinin de farklı (12. ay ve 6. ay) olmasına bağlı olabileceğini düşünmekteyiz.

Mevcut serimizde ortalama takip süresi $35.08 \pm$ 11.09 ay idi. Takip süresince kansere bağlı ölüm kaydedilmezken, genel sağkalım95.8\% olarak saptandi. Kompleks RENAL skorlu RPN uygulanan ve ortalama 16.5 ve 31 ay takipli serilerde bu oran $97.1 \%$ ve $94.8 \%$ ile bizim çalışmamızla benzerdi $(12,13)$.

Çalışmamızın bir takım kıstlamaları mevcuttu. Birincisi çalışmamızın retrospektif ve karşılaştırmasız bir çalışma olmasıydı. 
İkincisi vaka sayısının büyük merkezlere göre nisbete az olmasıydı. Üçüncüsü çalışmaya öğrenme eğrisi süresince opere edilen vakalarında dahil edilmesiydi.

Kısıtlayıc1 faktörlere rağmen sunmuş olduğumuz verilerin RYPN uygulamaya yeni başlayan ve başlayacak olan kliniklere yol göstermesi ve kompleks kitlelerde cesaret vermesi açısından literatüre katkı sağlayacağını düşünmekteyiz.

\section{SONUÇ}

Robot yardımlı parsiyelnefrektomi RENAL skoru orta-yüksek risk grubu renal kitlelerde güvenilir onkolojik ve fonksiyonel sonuçlarla başarıyla uygulanabilir cerrahi bir yöntemdir. Mevcut bulgularımızı destekleyecek prospektif karşılaştırmalı serilere ihtiyaç duyulmaktadır.

\section{REFERANSLAR}

1. Ljungberg B, Albiges L, Abu-Ghanem Y, et al. EuropeanAssociation of UrologyGuidelines on renalcellcarcinoma: the 2019 update. EurUrol. 2019;75:799-810.

2. Fero K, Hamilton ZA, Bindayi A, Murphy JD, Derweesh IH. Utilizationandqualityoutcomes of $\mathrm{cT}$ 1a, cT $1 \mathrm{~b}$ andcT 2a partialnephrectomy: analysis of thenationalcancerdatabase. BJU Int. 2018;121(4), 565-574.

3. Capitanio U, Terrone C, Antonelli A, et al. Nephronsparingtechniquesindependentlydecreasethe risk of cardiovasculareventsrelativetoradicalnephrectomy in patientswith a T1a-T1b renalmassand normal preoperativerenalfunction. Eur Urol.2015;67:683689.

4. Khalifeh A, Autorino R, Hillyer SP, Laydner H, Eyraud R, Panumatrassamee K. Comparativeoutcomesandassessment of trifecta in 500 roboticandlaparoscopicpartialnephrectomycases: a singlesurgeonexperience. J Urol 2013;189: 123642.

5. Takagi T, Kondo T, Tachibana H, et al. Robotassistedlaparoscopicversusopenpartialnephrectomy in patientswithchronickidneydisease: a propensityscore-matchedcomparativeanalysis of surgicaloutcomes. Int J Urol. 2017;24:505-510.

6. Kutikov A, Uzzo RG. The R.E.N.A.L. NephrometryScore: comprehensivestandardizedsystemforquantitatingren altumor size, locationanddepth. J Urol 2009;182:84453.

7. Levey AS, Bosch JP, Lewis JB, Greene T, Rogers N, Roth D.

\section{A} moreaccuratemethodtoestimateglomerularfiltration rate from serum creatinine: a newpredictionequation. Modification of Diet in RenalDiseaseStudyGroup. AnnInternMed 1999;130(6):461-70.

8. İslamoğlu E, Özsoy Ç, Karamık K, Erol İ, Ateş M, Savaş M. Robot-assistedPartialNephrectomy: Evaluation of SurgicalTechniqueandOncologicalOutcomes of Our First 56 Patients. Med J SDU 2018; 26(1): 72-79.

9. Buffi NM, Saita A, Lughezzani G, et al. Robotassistedpartialnephrectomyforcomplex (PADUA Score $\geq 10$ ) tumors: techniquesandresultsfrom a multicenterexperience at fourhigh-volumecenters. EurUrol. 2019. pii: S0302-2838(19)30192-7.

10. DiPierro GB, Tartaglia $\mathrm{N}$, Aresu $\mathrm{L}$ et al. Laparoscopicpartialnephrectomyforendophytichilart umors: feasibilityandoutcomes. Eur J SurgOncol 2014; 40: 769-74.

11. White MA, Haber GP, Autorino R et al. Outcomes of roboticpartialnephrectomyforrenalmasseswithnephro metryscore of $\geq 7$. Urology 2011; 77: 809-13.

12. Deng, W.,Li, J., Liu, X., Chen, L., Liu, W., Zhou, X., ... \&Wang, G. (2020). Robotassistedversuslaparoscopicpartialnephrectomyforana tomicallycomplex $\mathrm{T} 1 \mathrm{~b}$ renaltumorswith a RENAL nephrometryscore $\geq$ 7: A propensityscorebasedanalysis. CancerMedicine, 9(2), 586-594.

13. Wang, Y.,Ma, X., Huang, Q., Du, Q., Gong, H., Shang, J., \&Zhang, X. (2016). Comparison of robotassistedandlaparoscopicpartialnephrectomyforcompl exrenaltumourswith a RENAL nephrometryscore $\geq 7$ : peri-operativeandoncologicaloutcomes. BJU international, 117(1), 126-130.,

14. Ko KJ, Choi DK, Shin SJ, Ryoo HS, Kim TS, Song $\mathrm{W}$, et al. Predictivefactors of prolongedwarmischemic time $(\geq 30$ minutes $)$ duringpartialnephrectomyunderpneumoperitoneum. Korean J Urol, 2015;56(11), 742-748.

15. Thompson RH, Lane BR, Lohse CM, et al. Everyminutecountswhentherenalhilum clampedduringpartialnephrectomy. 2010;58(3):340-345., 